\title{
Interaction of Children with Toys to be Assembled: A Way to Promote the Development of Cognitive and Manual Skills
}

\author{
Laura Franchin $^{1}$, Cristina Donati ${ }^{2}$, Beatrice Benelli ${ }^{3}$, Federica Zobec ${ }^{1}$, Paola Berchialla ${ }^{3}$, Marisa Cemin ${ }^{4}$ \\ and Dario Gregori ${ }^{*}, 5$
}

\author{
${ }^{I}$ ZETA Research Ltd., Trieste, Italy \\ ${ }^{2}$ Istituto Italiano Sicurezza Giocattoli Ltd, Milano, Italy \\ ${ }^{3}$ Department of Public Health and Microbiology, University of Torino, Italy \\ ${ }^{4}$ Department of Psychology, University of Padova, Italy \\ ${ }^{5}$ Labs of Epidemiological Methods and Biostatistics, Department of Environmental Medicine and Public Health, \\ University of Padova, Italy
}

\begin{abstract}
The aim of the present study was to investigate the development of cognitive and manual skills in a sample of 48 children aged from 3 to 6 years in playing situations with toys to be assembled that usually are associated to edible products in the same packaging. The experimental observation made on children's manipulations in building these toys allowed us to investigate the development of cognitive skills during an object identification phase (when the parts of the toy are not assembled), the development of motor skills, observing the children's behavior mainly during the toy assembling phase, and finally the improvement of the child's self-esteem by analysing the children's verbal expressions and playing behaviors with the whole toy. The main results sustain an increasing of cognitive and fine motor skills during the years, and particularly an increasing of positive attitude that is fundamental for the child's self-esteem. The use of manipulative objects to be assembled seems to be a way to promote the development of specific fundamental childhood skills.
\end{abstract}

Keywords: Fine motor skills; assembling toys; children's self esteem.

\section{INTRODUCTION}

Toys serve a fundamental function in childhood development and playing is one of the most important aspects of a young child's life. In fact, children must use movement to learn about their world and this relationship with learning and movement is double fold, that is not only children move to learn but they also learn to move [1].

In the first years of life the "learn by making" is probably the most important mechanism that allows the child to improve his/her cognitive and motor skills. In particular, hand activities play a major role in early cognitive development [2]. The relationships between cognitive and manual performance have been extensively studied in infants [3-7] but it was less investigated in normal preschool and school children [2]. Based on the Piaget's assumptions that childhood cognitive development can be assessed by observing the complexity of activity with objects, Howes and Smith [8] positively tested the prediction that variation in infants and preschoolers' cognitive activities could be explained by different factors, among these the children's play activities. Consequently, manipulative toys represent an

*Address correspondence to this author at the Labs of Epidemiological Methods and Biostatistics, Department of Environmental Medicine and Public Health, University of Padova, Via Loredan 18, 35131 Padova, Italy; Tel: +39 049 8275384; Fax: +39 02700445089 ;

E-mail: dario.gregori@unipd.it interesting instrument through which children can improve their knowledge and skills, for example exploring mathematical and scientific concepts, such as number, size, and shape, through the direct manipulation of the physical objects [9].

Another important function of the mechanism "learn by making" is in the building processes of a child's selfconfidence, self-expression and self-esteem, in particular, in the first years with successful experiences in the motor domain [10-13]. Bunker [1], for example, assumed that children need experiences in putting things together, taking them apart, throwing things, catching things, and just moving themselves, and these challenges help develop their self-esteem. Movement activities, in fact, can provide opportunities for children to learn to feel confident about their skills [1].

Considering the important role of toys in the child development, the purpose of the present study was to investigate the development of cognitive and manual skills in preschoolers' playing situations. Studying the ability of young players to manipulate a toy, and specifically to assemble parts of a toy, could be a way to understand how the cognitive and manual skills develop during infancy. In fact, in the assembling activities, different fine motor, cognitive, perceptual, and communicative skills are involved and could be examinated. In the repeated manipulation of different toys, the child develops important specific (manual and cognitive) skills, such as size and colour discrimination, 
hand-eye coordination, imitation of people's behaviours and strategies, collaboration with other people, expression of his/her interests and attitudes, and control of his/her feelings.

For understanding the role of toys in the children's cognitive and manual development, in this study we decided to assess the interaction of preschoolers with special kinds of toys that were to be assembled. We chose very common toys, usually marketed in association with food, that are specifically targeted to age groups of about 3-8 years, and that are also well regulated in terms of safety. Further, to our knowledge, there is no research on the children behaviours' in relation with this kind of toys. Such toys involved in the experiment are small gadgets made up of several parts, which have to be assembled to obtain the whole object. The experimental observation made on the children's manipulations in building these toys allows investigating two main areas: 1) the development of cognitive skills during an object identification phase (when the parts of the toy are not assembled); 2) the development of motor skills, observing the child's behaviour during the assembling phase of the toy. Another aspect that this study allows us to investigate, thanks to the analysis of the children's verbal expressions and playing behaviours with the whole toy, is also the improvement or lack of improvement in the child's selfesteem.

\section{METHODS}

\section{Study Population}

A total of 48 children, 24 boys and 24 girls, aged from 3 to 6 years were included in the study (see Table 1 for a detailed description of the sample). None of them had any known developmental delays, based on parent report. The children were recruited from two local educational environments that gave permission for the study to be conducted in their facilities. Parent informed consent was obtained for all children prior to each child's participation in the study.

Table 1. Description of the Sample

\begin{tabular}{|c|c|c|c|l|}
\hline $\begin{array}{c}\text { Age } \\
\text { (Years) }\end{array}$ & $\mathbf{N}$ & $\begin{array}{c}\text { Boys } \\
(\mathbf{B})\end{array}$ & $\begin{array}{c}\text { Girls } \\
(\mathbf{G})\end{array}$ & \multicolumn{1}{|c|}{ Notes } \\
\hline \hline 3 & 12 & 6 & 6 & $1 \mathrm{~B}, 1 \mathrm{G}$ did not completed the test \\
\hline 4 & 12 & 6 & 6 & $1 \mathrm{G} \mathrm{did} \mathrm{not} \mathrm{completed} \mathrm{the} \mathrm{test}$ \\
\hline 5 & 12 & 6 & 6 & $\begin{array}{l}\text { 1 B, 2 G did not completed the test } \\
\text { G not wanted to start the test }\end{array}$ \\
\hline 6 & 12 & 6 & 6 & All children completed the test \\
\hline
\end{tabular}

\section{Testing Procedure}

Experimental sessions were conducted in a quiet room familiar to the children, outside of their classrooms, previously prepared with a hidden camcorder. All experimental sessions were video-recorded in the presence of two experimenters, one interacting with the child and another recording. During the experimental sessions, the child and the experimenter were seated next to each other at a child-sized table. Each session lasted approximately 30 minutes.
The experimenter presented to each child, one at a time, 4 different toys to be assembled. The toys could be a puzzle, a little plane, a car, a motor bike, a spaceship, a famous character or an animal (parrot, land snail, hedgehog, goose, butterfly, caterpillar). These objects were composed of small parts (ranging between four and eight) to be assembled. The toys composed of few parts (e.g. famous characters)were more simple to be assembled than those composed of several parts (e.g. puzzles), offering to the child tasks with different difficulty levels. All toys satisfied the EU Safety of Toys Directive [14].

\section{Experimental Observations}

The experiment consisted of observing the behaviour of the children when exposed to each object to assemble. First, the experimenter observed if the child recognized what kind of toy he/she had found (toy identification phase). Second, the child's assembling skills were evaluated, starting from the looking at the instruction consisting of drawings to the assembly of the toy (assembling phase). Finally, how the child plays with the toy was evaluated (play phase). All the behaviours that were possible to observe for each phase are schematically reported in Table 2 . The experimenter noticed the behaviour exhibited by the child, indicating in a score sheet the presence or the absence of each behaviour reported in Table 2, for all the four presented toys. A second off-line video analysis was made by another experimenter who noticed the child's behaviour and particular verbal expressions that the child expressed.

\section{Statistical Methods}

Descriptive statistics, like absolute numbers and percentages were worked out. In order to assess differences between age groups in performing manual tasks, we considered to have/not to have completed the task the outcome of interest. Thus, linear mixed effects models, which took into account individual variability and variability which arose from different tests, were carried for each tasks. Statistical significance was considered at $p \leq 0.05$. Statistical analysis was performed using R.

\section{RESULTS}

A general description of the results is showed in Fig. (1). In order to understand how the interaction of children with toys to be assembled develops over the preschool years, a qualitative analysis of the video tapes was used for each studied age. Following more qualitative details about children behaviours' all over the tests are reported.

At three years of age, during the toy identification phase, almost half of the sample usually did not recognize the object to assemble, or the experimenter had to identify it first, because the child said that he/she had no idea of what it was. In the assembling phase, many of the 3-yearsoldchildrentook the toy instructions, looked at it and gave it to the experimenter. Then, the children displayed different behaviours while looking at the four toys, which were administered at different times: sometimes they only touched or moved some parts of the toy; almost always they tried to assemble at least one toy, but the result was negative for half of the sample. Very few children did not try to assemble or touch the toy. During this phase, particularly at the beginning, many children verbally expressed their inability 
Table 2. Child's Observed Behavior During Different Phases

\begin{tabular}{|l|l|}
\hline \multicolumn{1}{|c|}{ Phases } & \multicolumn{1}{|c|}{ Observed Behaviors } \\
\hline \hline \multirow{3}{*}{ 1. Toy identification } & - Child identifies first; \\
& - Child does not identify correctly, and experimenter helps him/her to identify; \\
& - Experimenter identifies first. \\
\hline & - Child looks at the instructions or gives it to the experimenter; \\
& - Child moves or only touches the parts of the toy; \\
& - Child tries to assemble the parts but the result is negative; \\
& - Child tries to assemble and with the experimenter helping, the result is positive; \\
& - Child tries to assemble only few parts of the toy; \\
& - Child assembles all the parts by himself/herself; \\
& - Child does not try to assemble. \\
\hline \multirow{3}{*}{ 2. Assembling } & - Child plays alone with the toy; \\
& - Experimenter shows to the child how he/she can play, and the child imitates the experimenter; \\
& - Child is not interested by the toy and does not play. \\
\hline
\end{tabular}

\section{Children who passed at least one test}

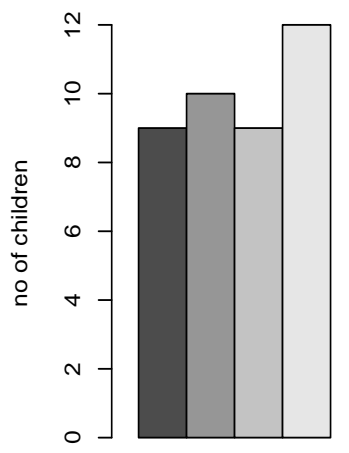

Toy identification

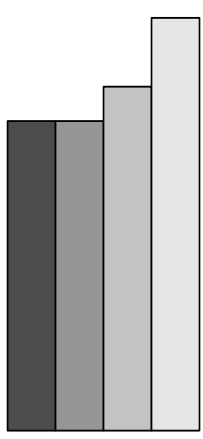

Assembling

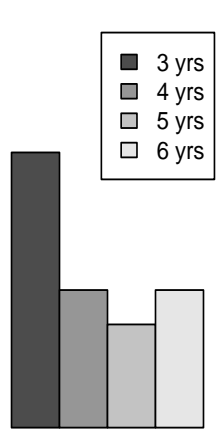

Play

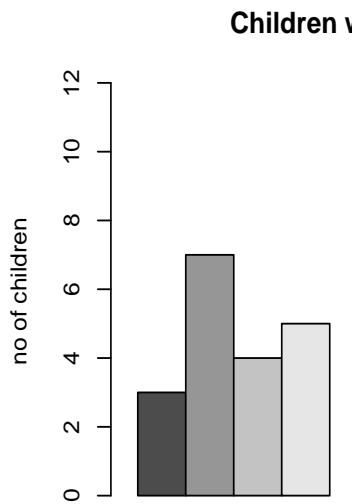

Toy identification

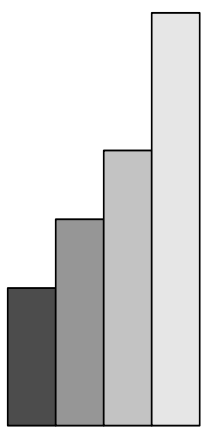

Assembling

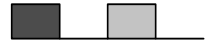

Play
Children who passed at least three tests

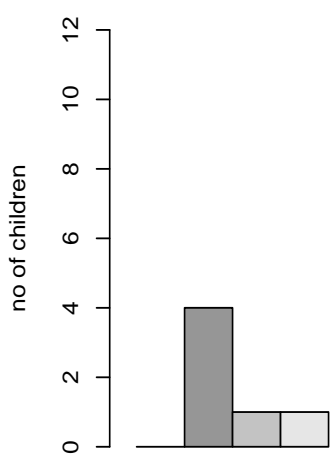

Toy identification

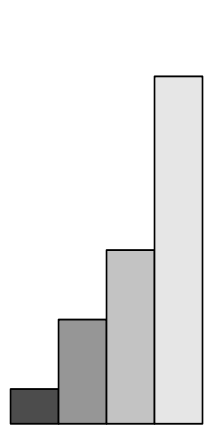

Assembling

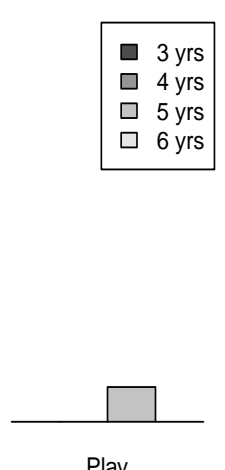

Play

Children who passed all four tests

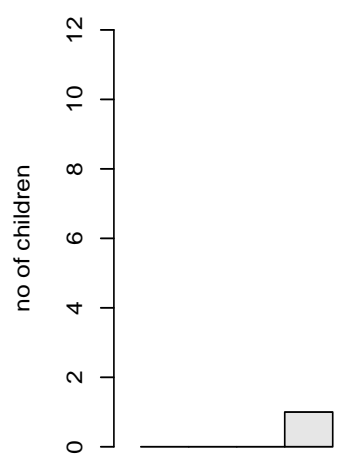

Toy identification

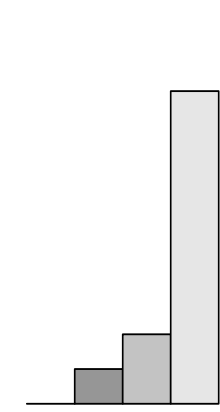

Assembling

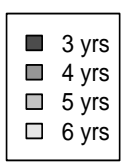

3 yrs
4 yrs

$5 \mathrm{yrs}$

Fig. (1). Number of children who passed at one test (top left), two tests (top right), three tests (bottom left) and all four test (bottom right).

to assemble the toy, but when the experimenter offered to help them, many exhibited collaborative behaviour. Finally, almost all the children (nine out of twelve) played with the toys by themselves or, if they did not understand the functioning of the play, they imitated the experimenter's playing behaviour. 
At the age of four, during the toy identification phase, ten children identified the object to assemble at least one time. In the assembling phase, some children looked at the instructions, while other tried to immediately assemble the object. For 9 children the assembling phase was successful more than one time, thanks to the experimenter's help. Only one child was able to assemble one toy completely by himself. Few children did not have positive results, some were unable to assemble a toy, others assembled only some parts of the toy, and others only touched them without trying to assemble. Very few children did not try to assemble or touch the toy. At the beginning of this phase, some children expressed their incapability to assemble the toy, but when the experimenter offered her help, a lot of them exhibited a collaborative behaviour. It is interesting to note that one child described the assembling operations out loud while he was making the toy. Finally, four children played with the toys by themselves at least one time.

At age five, for the toy identification and the assembling phase, the children's behaviour was similar to those of the fouryear-olds. However, three children in this subgroup were able to assemble the toy completely by themselves, without the experimenter's help, at least one time. Only one child was unable to assemble a toy, a few of them sometimes assembled only some parts of the toy, and nobody only touched the toys without trying to assemble. Only two children did not try to assemble one of the toys. None of the five-year-old children expressed his/her inability to assemble the toy. They exhibited high concentration or, if the toy was boring for them, inattention. Finally, three children played at least once with the toys by themselves, some of them instead preferred simply to look at the toy, proud of their exhibited ability.

At the age of six, for the toy identification phase, all children at least once identified the object to assemble. At the beginning of the assembling phase, the majority of children immediately assembled the object without looking at the instructions. For nine children the assembling phase was successful more than one time (passed all four tests), thanks to the experimenter's help; ten children were able to assemble the toy completely by himself at least once, while two with the help of the experimenter. Only one child was not able to assemble one toy. Nobody only assembled some parts of a toy, touched them without trying to assemble them, or just did not try to assemble at all. None of the six-year-old children expressed their inability to assemble the toy, while one child described out loud the assembling operations while he was making the toy. Finally, four children played at least once with the toys by themselves, some of them preferred instead to simply look the toy, proud of their exhibited ability.

A mixed model has been implemented in order to assess differences between age group. As reported in Table 3, no statistically significant differences arose between age groups during the phase of toy identification. While assembling toy, statistically significant differences were found between children at three years old and children at five and six years old. In the model, adjustment was made for sex.

\section{DISCUSSION}

The aim of the study was to assess the interaction of children at 3, 4, 5, and 6 years of age with small toys to be assembled in order to study the cognitive, manual and selfesteem development. The main result obtained is that at these four ages the ability to identify the object to assemble, the manipulation of the toys, and the children's verbalizations about their self-esteem on the task consistently change.

At 3 years, children show difficulties both in identifying and assembling the toys (e.g., some of them simply prefer only to touch or move different parts of the toy). During the years until age six the behaviour changes. At 6 years, in fact, most of the children are able to identify the object and a lot of them are able to assemble the toys by themselves, without adult help. Regarding these data, it is possible to note, during the years, the increase of cognitive skills (in the toy identification phase, even if statistical significance is not reached) and fine motor skills (in the assembling phase).

This result also highlights the different degree of cognitive complexity of children's play. The different behaviours exhibited by different age groups seem to be consistent with the first two types of play elaborated upon the original Piaget categories (see [15]), by Smilansky [16]: a) functional play, simple repetitive activities with or without objects, exercising already existing schemas (i.e., moving cars); (b) constructive play, manipulation of objects to construct or to create something (i.e., putting together plastic blocks to make a train). This last kind of play involves sensorimotor skills and symbolic representations $[15,16]$. As we found in our sample, Rubin, Maioni and Hornung [17] underlined that the functional play appears ontogenetically first in infancy, while constructive play and other categories of play (such as dramatic play and games with rules, see [16]) last.

Another consideration that is possible to advance, regards the last play phase. Three-year-old children, at the end of the

Table 3. Results from Mixed Effect Model

\begin{tabular}{|c|c|c|c|c|c|c|}
\hline & \multicolumn{3}{|c|}{ Toy Identification } & \multicolumn{2}{c|}{ Assembling } \\
\cline { 2 - 7 } & Estimate & Std. Error & p-Value & Estimate & Std. Error & p-Value \\
\hline \hline (Intercept) & -0.188 & 0.620 & 0.762 & -1.251 & 0.644 & 0.052 \\
\hline 4 year old & 1.525 & 0.823 & 0.064 & 0.917 & 0.722 & 0.838 \\
\hline 5 yrs old & 1.785 & 0.932 & 0.056 & 2.732 & 1.107 & $<0.001$ \\
\hline 6 yrs old & 1.523 & 0.799 & 0.057 & 4.507 & 1.396 & 0.620 \\
\hline sex (male) & 0.648 & 0.633 & 0.306 & 0.024 \\
\hline
\end{tabular}


assembling phase, particularly preferred playing with the toys. In the other ages, 6-year-olds in particular, some children played with the toys, but others preferred looking at the toys, with a satisfied expression in achieving their final result. It is possible to hypothesize that these two different behaviours reflect, other than the different playing activities during the ages, also the positive attitude that characterized the older children and that is fundamental to their increasing self-esteem. It seems that for the older children, the more amusing phase is to assemble and not to play with the toy itself, probably because the toys were very simple objects.

During all phases, the younger children exhibited more interactions with the experimenter than the older ones. For example, they often asked an help to construct the toy and also they exhibited more collaborative behaviours than the 6year-olds, trying to help the experimenter (e.g., giving to her the instructions, or some parts of the toys) or playing with her, even if with imitative behaviours. It seems that younger children need a positive interaction with an adult to have fun with the toys, while older children enjoy themselves with less interactive behaviours, focusing themselves more on the toy. The 6-year-olds exhibit, in fact, more an "I do by myself" behaviours, reflecting in this age an increasing of desire of autonomy.

In addition, interesting data was also derived by the experimenter notes on the children's verbalizations. A lot of 3 year-old children expressed their inability, saying in the majority of cases "I'm not able to do this", while in the other stages these verbalizations decrease until they almost disappear by the age of six. Three-year-olds have less experience with these toys and their motor and cognitive systems (in particular, the executive functions such as inhibitory control, working memory, set-shifting) are less developed than the other ages, and for that reason they could limit the children's ability in mental planning [18] and, consequently, in assembling the toys. The executive functions in fact encompass abilities needed for goaldirected behavior such as inhibition, planning, strategy development, persistence, and flexibility of action [19]. In assembling tasks, first children have to identify the steps needed to reach a goal that is in the present study the toy construction, in other words the children must to be able to plan and develop a strategy. Three-year-old children probably are not always able to identify these steps (even if it depends from the type of the toy to assemble and from the planning request by the task) and for that reasons, they feel inadequate for the task, whereas the older children, and particularly the 6-year-olds, feel confident. The older children probably feel more capable first of all for their more developed motor and cognitive systems. Secondarily, it is probably that they also have had similar experiences with manipulating these types of toys. Even if the experience factor (on the previous toys that children have assembled) is not adequately investigated in this study, it is plausible to assume that it could play an important role in the children's self-confidence and self-esteem during these tasks. Some intriguing considerations could be advanced if further investigations will analyse the development of the emotional aspects and self-esteem feelings involved in playing behaviours.
Another aspect that emerged in this study and that would be very interesting to further investigate is the interaction between the manual and verbal (mental planning) operations. We found three children at 4 and 5 years of age who, while they were assembling the toy, described what they were doing. As we hypothesised, at the age of three, children are not able to realize an operative "mental program" to assemble the toy, because, first of all, they probably don't have a symbolic representation of the whole toy (according to Piaget' assumptions). At the ages of 4-5 they begin to construct some intuitive mental strategies to reach the final goal, they start to consider alternative means of solving the problem and they probably are more able to select the right approach to reach the final goal. During this mental planning, some of them need to externalize these operations in a verbal way. The language involvement in the manipulation could serve different functions, such as to simply reflect the mental planning (like a realization of what they are doing in order to reach the final result), or to pay more attention to what they are doing (such as the cognitive system telling the motor system what to do). At 6 years, these cognitive processes seem to become automatic, and for that reason the children do not need to explain verbally what they are doing. In future research, particular attention could be focused on the understanding of the development of logical operations during manual activities like that investigated in this study.

Finally, we think that this study has improved our knowledge about childhood cognitive and manual development. The small toys to be assembled that children usually find marketed with commercial food could be supposed to be a way to promote the development of cognitive and manual skills and also feelings of selfconfidence, self-expression and self-esteem. There are still a lot of aspects to be investigated for future research, one of these could be the study of the development of children mental planning abilities during playing activities and, in particular, the development of the relations existing between cognitive and manual skills during the toys assembling.

\section{REFERENCES}

[1] Bunker LK. The role of play and motor skill development in building children's self-confidence and self-esteem. Element School J 1991; 91(5): 467-71.

[2] Dellatolas G, De Agostini M, Curt F, et al. Manual skill, hand skill asymmetry, and cognitive performances in young children. Laterality 2003; 8: 317-38.

[3] Bushnell E, Boudreau JP. Motor development and the mind: the potential role of motor abilities as a determinant of aspects of perceptual development. Child Dev 1993; 64: 1005-21.

[4] Gibson EJ. Exploratory behavior in the development of perceiving, acting, and the acquiring of knowledge. Ann Rev Psychol 1988; 39: $1-41$

[5] Piaget J. The origins of intelligence in children. New York: International University Press 1952.

[6] Ruff H. The infant's use of visual and haptic information in the perception and recognition of objects. Can J Psychol 1989; 43: 302-19.

[7] Thelen E. Motor development: a new synthesis. Am Psychol 1995; 50: 79-95.

[8] Howes C, Smith EW. Relations among child care quality, teacher behavior, children's play activities, emotional security, and cognitive activity in child care. Early Child Res Q 1995; 10: 381 404.

[9] Resnick M, Fred M, Robert B, et al. Digital manipulatives: new toys to think with. In: Proceedings of the SIGCHI conference on 
Human Factors in Computing Systems, April 18-23. Los Angeles, USA 1998; pp. 281-7.

[10] Ackermann E. Perspective taking and object construction. In: Kafai YB, Resnick M, Eds. Constructionism in Practice: designing, thinking and learning in a digital world. Mahwah, NJ: Erlbaum 1996; pp. 25-36.

[11] Ackermann E. Constructing knowledge and transforming the world. In: Tokoro M, Steels L, Eds. Future Learn. Amsterdam: IOS Press 2004; pp. 15-35.

[12] Harel I, Papert S. Constructionism Norwood. NJ: Ablex 1991.

[13] Resnick M. Rethinking learning in the digital age. In: Kirkman G, Ed. The global information technology report: readiness for the networked world. New York: Oxford University Press 2002; pp. 32-7.
[14] European Commission, Council Directive 88/378/EEC on Toy Safety. Offic J 1988; 187: 0001-13.

[15] Piaget J. Play, dreams, and imitation in childhood. New York: Norton 1962.

[16] Smilansky S. The effects of sociodramatic play on disadvantaged children: preschool children. New York: Wiley 1968.

[17] Rubin KH, Maioni TL, Hornung M. Free play behaviors in middleand lower-class preschoolers: Parten and Piaget revisited. Child Dev 1976; 47: 414-9.

[18] Malloy-Diniz LF, Cardoso-Martins C, Nassif EP, Levy AM, Leite WB, Fuentes D. Planning abilities of children aged 4 years and 9 months to $81 / 2$ years. Dement Neuropsychol 2008; 2(1): 26-30.

[19] Brocki KC, Bohlin G. Executive Functions in children aged 6 to 13: a dimensional and developmental study. Dev Neuropsychol 2004; 26(2): 571-93.

(C) Franchin et al.; Licensee Bentham Open.

This is an open access article licensed under the terms of the Creative Commons Attribution Non-Commercial License (http: //creativecommons.org/licenses/ by-nc/3.0/) which permits unrestricted, non-commercial use, distribution and reproduction in any medium, provided the work is properly cited. 